\title{
Correlation analysis between disease severity and clinical and biochemical characteristics of 143 cases of COVID-19 in Wuhan, China: a descriptive study
}

Dan Wang ${ }^{1}$, Ruifang $\mathrm{Li}^{1}$, Juan Wang ${ }^{2}$, Qunqun Jiang ${ }^{3}$, Chang Gao ${ }^{1}$, Juan Yang ${ }^{1}$, Lintong Ge ${ }^{1}$ and Qing Hu ${ }^{1 *}$ (1)

\begin{abstract}
Background: Coronavirus disease 2019 (COVID-19) is a novel infectious disease caused by the severe acute respiratory syndrome coronavirus 2 (SARS-CoV-2) emerged in Wuhan and has quickly spread across the world. The mortality rate in critically ill patients with COVID-19 is high. This study analyzed clinical and biochemical parameters between mild and severe patients, helping to identify severe or critical patients early.

Methods: In this single center, cross-sectional study, 143 patients were included and divided to mild/moderate and sever/critical groups. Correlation between the disease criticality and clinical features and peripheral blood biochemical markers was analyzed. Cut-off values for critically ill patients were speculated through the ROC curve.

Results: Significantly, disease severity was associated with age $(r=0.458, P<0.001)$, comorbidities $(r=0.445, P<0.001)$, white cell count $(r=0.229, P=0.006)$, neutrophil count $(r=0.238, P=0.004)$, lymphocyte count $(r=-0.295, P<0.001)$, albumin $(r=-0.603, P<0.001)$, high-density lipoprotein cholesterol $(r=-0.362, P<0.001)$, serum potassium $(r=-$ $0.237, P=0.004)$, plasma glucose $(r=0.383, P<0.001)$, total bilirubin $(r=0.340, P<0.001)$, serum amyloid $A(r=0.58$, $P<0.001)$, procalcitonin $(r=0.345, P<0.001)$, C-reactive protein $(r=0.477, P<0.001)$, lactate dehydrogenase $(r=0.548$, $P<0.001)$, aspartate aminotransferase $(r=0.342, P<0.001)$, alanine aminotransferase $(r=0.264, P=0.001)$, erythrocyte sedimentation rate $(r=0.284, P=0.001)$ and D-dimer $(r=0.477, P<0.001)$.

Conclusions: With the following parameters such as age $>52$ years, C-reactive protein $>64.79 \mathrm{mg} / \mathrm{L}$, lactate dehydrogenase $>245 \mathrm{U} / \mathrm{L}$, D-dimer $>0.96 \mu \mathrm{g} / \mathrm{mL}$, serum amyloid A $>100.02 \mathrm{mg} / \mathrm{L}$, or albumin $<36 \mathrm{~g} / \mathrm{L}$, the progress of COVID-19 to critical stage should be closely observed and possibly prevented. Lymphocyte count, serum potassium, high-density lipoprotein cholesterol and procalcitonin may also be a prognostic indicator.
\end{abstract}

Keywords: SARS-CoV-2, COVID-19, Correlation analysis, Prognostic indicator

\footnotetext{
* Correspondence: hqzsyy@126.com

'Department of Neurology, Hubei NO.3 People's Hospital of Jianghan University, 26 Zhongshan Road, Qiaokou District, Wuhan, China

Full list of author information is available at the end of the article
}

C C The Author(s). 2020 Open Access This article is licensed under a Creative Commons Attribution 4.0 International License, which permits use, sharing, adaptation, distribution and reproduction in any medium or format, as long as you give appropriate credit to the original author(s) and the source, provide a link to the Creative Commons licence, and indicate if changes were made. The images or other third party material in this article are included in the article's Creative Commons licence, unless indicated otherwise in a credit line to the material. If material is not included in the article's Creative Commons licence and your intended use is not permitted by statutory regulation or exceeds the permitted use, you will need to obtain permission directly from the copyright holder. To view a copy of this licence, visit http://creativecommons.org/licenses/by/4.0/ The Creative Commons Public Domain Dedication waiver (http://creativecommons.org/publicdomain/zero/1.0/) applies to the data made available in this article, unless otherwise stated in a credit line to the data. 


\section{Background}

A novel coronavirus, designated as the severe acute respiratory syndrome coronavirus 2 (SARS-CoV-2), was first identified in Wuhan, China in December 2019 [1]. SARS$\mathrm{CoV}-2$ is highly infectious and asymptomatic patients may also become the source of infection [2]. World Health Organization (WHO) announced that the disease caused by SARS-CoV-2 was coronavirus disease 2019 (COVID19) on February 11, 2020. Patients with COVID-19 have a series of clinical manifestations, such as pharyngalgia, fever, cough, fatigue, anorexia, headache, diarrhea, nausea or vomiting, dyspnea [3], even acute respiratory distress syndrome (ARDS). A lot of severe or critical patients had to been admitted to the intensive care unit (ICU). According to the reported clinical characteristics of patients with COVID-19, the total mortality ranges from 2 to $5 \%$, which can be even higher in the elders [4]. Wuhan city, as the epidemic area, the mortality reached a peak of over $7 \%$ at the early stage [5].

Although most patients with COVID-19 were mild in the early days, some patients progressed rapidly to acute respiratory failure, metabolic acidosis, septic shock, ARDS or death. Early identification of risk factors for critical patients could facilitate appropriate supportive care and thus reduce the mortality [6]. A study of the first 138 laboratory-confirmed cases with COVID-19 showed the changes of neutrophil count, lymphocyte count, and D-dimer levels [7]. Increased inflammation -related indicators were found in patients with COVID19, including erythrocyte sedimentation rate (ESR), interleukin-6 and C-reactive protein (CRP) [4]. However, little is known about the relationship between disease severity and clinical and biochemical features in patients with COVID-19.

In this study, we performed a comprehensive evaluation of characteristics of 143 patients with COVID-19 admitted to Hubei NO.3 People's Hospital of Jianghan University, Wuhan. This study retrospectively analyzed clinical characteristics and biochemical parameters between mild/moderate and severe/critical patients, which may help to identify critical cases and perform appropriate clinical intervention early.

\section{Methods}

\section{Study design and participants}

This study was a cross-sectional study, and all consecutive patients with confirmed COVID-19 admitted to Hubei NO.3 People's Hospital of Jianghan University from January 15, 2020 to February 28, 2020, were enrolled. Hubei NO.3 People's Hospital of Jianghan University, located in Wuhan, Hubei Province, the endemic areas of SARS-CoV-2, is one of the major public hospitals and is responsible for the treatments for COVID-19 assigned by the government. Diagnosis of COVID-19 and clinical classification according to the new coronavirus pneumonia diagnosis and treatment plan (trial version 7) developed by the National Health Commission of the People's Republic of China [8].

The clinical classifications are as follows: (1) mild, minor symptoms and imaging shows no pneumonia. (2) moderate, with fever, respiratory tract symptoms, and imaging shows pneumonia. (3) severe, meet any of the following: a) respiratory distress, respiratory rate $\geq 30$ beats $/ \mathrm{min}$; b) in the resting state, means oxygen saturation $\leq 93 \%$; c) arterial blood oxygen partial pressure/oxygen concentration $\leq$ $300 \mathrm{mmHg}(1 \mathrm{mmHg}=0.133 \mathrm{kPa}) ; \mathrm{d})$ pulmonary imaging showed that the lesion progressed more than $50 \%$ within 24-48 h. (4) critical, one of the following conditions: a) respiratory failure occurs and requires mechanical ventilation; b) Shock occurs; c) ICU admission is required for combined organ failure.

In this study, the patients with mild or moderate symptoms were classified as mild/moderate group, and the patients with severe or critical symptoms were classified as severe/critical group. The assessment of disease severity and laboratory tests were performed at the same time on the day of inpatient admission before treatment.

\section{Data collection}

All suspected infection patients were taken upper respiratory throat swab samples at admission and then shipped to designated authoritative laboratories to detect the SARS-CoV-2. Bacterial and fungal detections of sputum or respiratory secretions and other laboratory tests were completed in the clinical laboratory in Hubei NO.3 People's Hospital of Jianghan University. C-reactive protein (CRP) was detected by immunoturbidimetry method. Procalcitonin (PCT) was detected by Roche electrochemiluminescence method. Erythrocyte sedimentation rate (ESR) was measured by Westergren's international standard method.

We retrospectively analyzed and evaluated the epidemiological history, comorbidities, vital signs, and symptoms obtained from electronic medical records. The data collection forms were reviewed independently by two experienced physicians. These patients have not been reported in any other submission by anyone.

\section{Statistical analysis}

Categorical variables were given as frequency rates and percentages; continuous variables were defined using mean, median, and interquartile range (IQR) values. The Kolmogorov-Smirnov test was used to verify the normality of distribution of continuous variables. The independent sample $t$ test or the Mann-Whitney $U$ test was used for the continuous variables and the chi-square test for the categorical variables. In correlation analysis, Pearson correlation coefficient was used for the variables 
of normal distribution and Spearman correlation coefficient for those of skewed distribution. Receiver-operating characteristic (ROC) curve analysis was used to determine the optimum cut-off points of parameters for severe patients. Statistical analyses were performed using SPSS 24.0 (SPSS Inc., Chicago, IL, USA) and MedCalc 19.0.4. A 2 -tailed $P<0.05$ was considered as statistically significant.

\section{Results}

The study population included 143 hospitalized patients with confirmed COVID-19. The median age was 58 years (IQR, 39-67; range, 14-84 years), and 73 (51.0\%) were men. Of the 143 patients, $50(35.0 \%)$ had 1 or more comorbidities. Hypertension (36 [25.2\%]), cardiovascular disease (16 [11.2\%]) and diabetes (13 [9.1\%]) were the most common coexisting conditions. The most common symptoms at initial stage of illness were fever (137 [95.8\%]), fatigue (93 [65.0\%]), dry cough (78 [54.5\%]), anorexia (66 [46.2\%]), chest tightness (63 [44.1\%]), myalgia (49 [34.3\%]), mild shortness of breath (48 [33.6\%]), chill (33 [23.1\%]) and dyspnea (31 [21.7\%]). Less common symptoms were nausea or vomiting, diarrhea and headache (Table 1). X-ray or CT showed multiple lung lobes or bilateral involvement in 138 (96.5\%) patients. Figure 1 showed the CT images of a typical patient in early, consolidation, absorption and dissipation stages.

Compared with the mild/moderate group $(n=72)$, the severe/critical group $(n=71)$ were significantly older (median age, 65 years [IQR, 53-69] vs 44 years [IQR,

Table 1 Demographics and baseline characteristics of patients with COVID-19

\begin{tabular}{|c|c|c|c|c|}
\hline & \multicolumn{3}{|l|}{ No. (\%) } & \multirow{2}{*}{$\begin{array}{l}\boldsymbol{P} \\
\text { Value } \\
\mathbf{a}\end{array}$} \\
\hline & Total $(\boldsymbol{N}=143)$ & Mild/Moderate $(\boldsymbol{n}=72)$ & Severe/Critical( $(n=71)$ & \\
\hline Age, median (IQR), y & $58(39-67)$ & $44(32-60)$ & $65(53-69)$ & 0.000 \\
\hline Sex & & & & 0.009 \\
\hline Female & $70(49.0)$ & $43(59.7)$ & $27(38.0)$ & \\
\hline Male & $73(51.0)$ & $29(40.3)$ & $44(62.0)$ & \\
\hline Huanan Seafood Wholesale Market exposure & $11(7.7)$ & $4(5.6)$ & $7(9.7)$ & 0.359 \\
\hline Comorbidities & $50(35.0)$ & $10(13.9)$ & $40(56.3)$ & 0.000 \\
\hline Hypertension & $36(25.2)$ & $5(6.9)$ & $31(43.7)$ & 0.000 \\
\hline Cardiovascular disease & $16(11.2)$ & $4(5.6)$ & $12(16.9)$ & 0.031 \\
\hline Diabetes & $13(9.1)$ & $4(5.6)$ & $9(12.7)$ & 0.139 \\
\hline Chronic obstructive pulmonary disease & $10(7.0)$ & $3(4.2)$ & $7(9.9)$ & 0.091 \\
\hline Cerebrovascular disease & $5(3.5)$ & $2(2.8)$ & $3(4.2)$ & 0.987 \\
\hline \multicolumn{5}{|l|}{ Signs and symptoms } \\
\hline Fever & $137(95.8)$ & $70(97.2)$ & $67(94.4)$ & 0.619 \\
\hline Fatigue & $93(65.0)$ & $42(58.3)$ & $51(71.8)$ & 0.091 \\
\hline Dry cough & $78(54.5)$ & $37(51.4)$ & $41(57.7)$ & 0.455 \\
\hline Anorexia & $66(46.2)$ & $23(31.9)$ & $43(60.6)$ & 0.001 \\
\hline Chest tightness & $63(44.1)$ & $29(40.3)$ & $34(47.9)$ & 0.359 \\
\hline Myalgia & $49(34.3)$ & $18(25.0)$ & $31(43.7)$ & 0.019 \\
\hline Mild shortness of breath & 48 (33.6) & $33(45.8)$ & $15(21.1)$ & 0.002 \\
\hline Chill & $33(23.1)$ & $19(26.4)$ & $14(19.7)$ & 0.344 \\
\hline Dyspnea & $31(21.7)$ & $10(13.9)$ & $21(29.6)$ & 0.023 \\
\hline Pharyngalgia & 28 (19.6) & $12(16.7)$ & $16(22.5)$ & 0.377 \\
\hline Diarrhea & $26(18.2)$ & $12(16.7)$ & $14(19.7)$ & 0.636 \\
\hline Expectoration & $22(15.4)$ & $5(6.9)$ & $17(23.9)$ & 0.005 \\
\hline Nausea or Vomiting & $14(9.8)$ & $7(9.7)$ & $7(9.9)$ & 0.978 \\
\hline Headache & $7(4.9)$ & $3(4.2)$ & $4(5.6)$ & 0.985 \\
\hline Multiple lung lobe or bilateral involvement & $138(96.5)$ & $68(94.4)$ & 70 (98.6) & 0.371 \\
\hline Onset of symptom to Hospital admission, median (IQR), d & $5(3-7)$ & $4(3-5)$ & $6(5-7)$ & 0.000 \\
\hline
\end{tabular}

Abbreviations: IQR interquartile range, COVID-19 Coronavirus disease 2019

a $P$ values indicate differences between mild/moderate and severe/critical. $P<0.05$ was considered statistically significant 


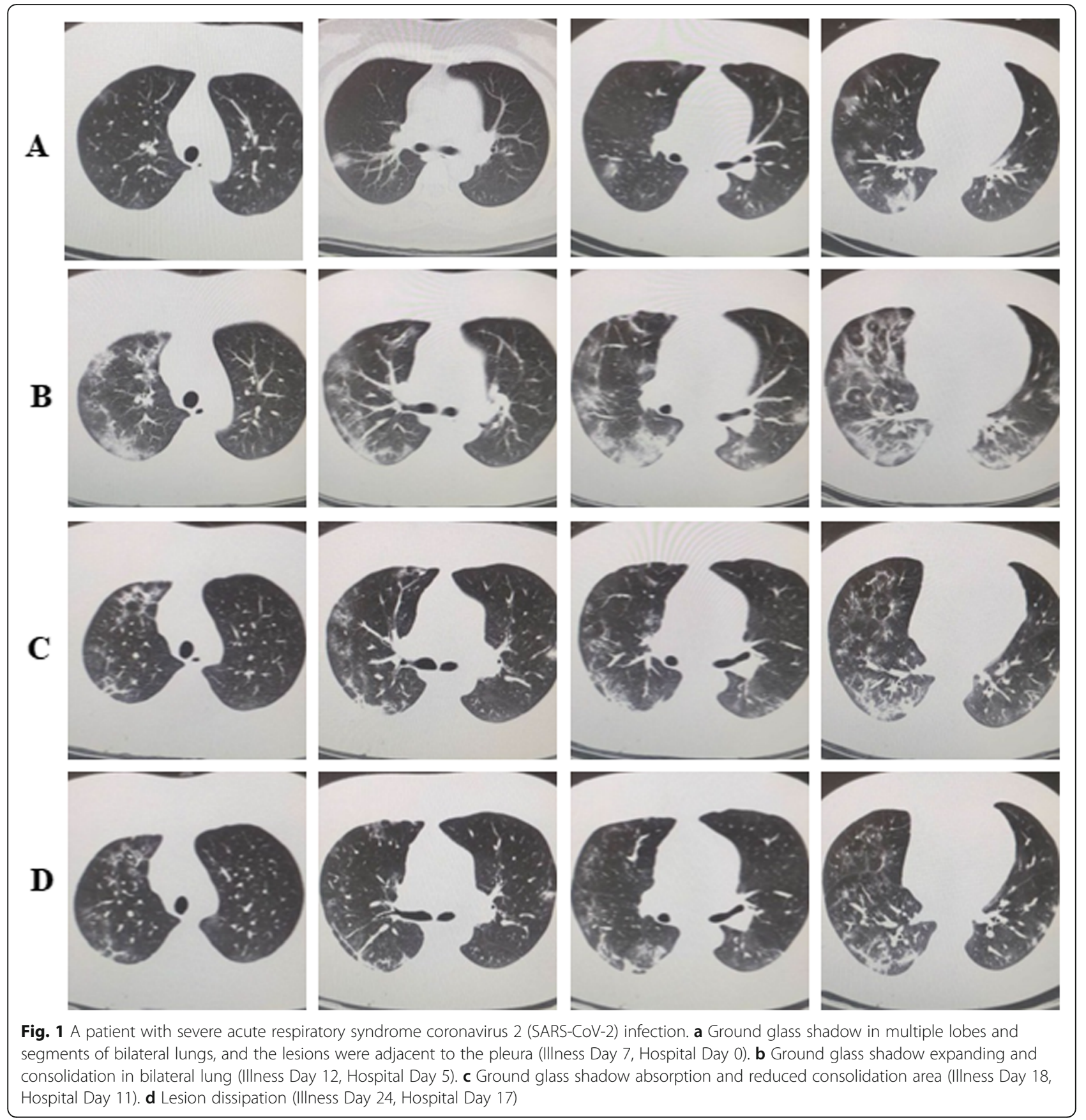

32-60]; $P<0.001)$ and were more likely to have underlying comorbidities, including hypertension (31 [43.7\%] vs 5 [6.9\%], and cardiovascular disease $(12[16.9 \%]$ vs 4 [5.6\%]). Compared with the mild/moderate group, the severe/critical group were more likely to report anorexia, expectoration, mild shortness of breath, dyspnea and myalgia.

There were numerous differences in laboratory findings between mild/moderate group and severe/critical group, including white blood cell, neutrophil count, and lymphocyte count, as well as levels of high-density lipoprotein cholesterol (HDL-C), plasma glucose, serum potassium, total bilirubin (TBIL), albumin, aspartate aminotransferase (AST), alanine aminotransferase (ALT), lactate dehydrogenase (LDH), D-dimer, erythrocyte sedimentation rate (ESR), serum amyloid A (SAA), C-reactive protein (CRP) and procalcitonin (PCT) (Table 2).

Significant correlations were found about age, comorbidities, white blood cell count, neutrophil count, lymphocyte count, plasma glucose, serum potassium, albumin, D-dimer, HDL-C, TBIL, AST, ALT, LDH, ESR, SAA, CRP and PCT. Strikingly, this analysis revealed 
Table 2 Laboratory findings of patients with COVID-19 on admission to hospital

\begin{tabular}{|c|c|c|c|c|c|}
\hline & \multirow{2}{*}{$\begin{array}{l}\text { Normal } \\
\text { Range }\end{array}$} & \multicolumn{3}{|l|}{ Median (IQR) } & \multirow{2}{*}{$\begin{array}{l}P \\
\text { Value }^{\mathbf{a}}\end{array}$} \\
\hline & & Total $(\boldsymbol{N}=143)$ & Mild/Moderate $(\boldsymbol{n}=72)$ & Severe/Critical $(\boldsymbol{n}=71)$ & \\
\hline White blood cell count, $\times 10^{9} / \mathrm{L}$ & $3.5-9.5$ & $3.8(3.2-5.8)$ & $3.6(3.2-4.4)$ & $4.6(3.2-7.3)$ & 0.006 \\
\hline Neutrophil count, $\times 10^{9} / \mathrm{L}$ & $1.8-6.3$ & $3.7(2.2-5.6)$ & $3.2(2.2-4.5)$ & $4.5(2.4-6.6)$ & 0.005 \\
\hline Lymphocyte count, $\times 109 / L$ & $1.1-3.2$ & $0.9(0.6-1.2)$ & $1.1(0.7-1.3)$ & $0.7(0.6-1.0)$ & 0.000 \\
\hline Monocyte count, $\times 109 / \mathrm{L}$ & $0.1-0.6$ & $0.3(0.2-0.4)$ & $0.3(0.2-0.4)$ & $0.3(0.2-0.4)$ & 0.816 \\
\hline Hemoglobin, g/L & $115-150$ & $123(119-133)$ & $124(119-136)$ & $123(116-130)$ & 0.118 \\
\hline Platelet count, $\times 109 / \mathrm{L}$ & $125-350$ & $155(128-230)$ & $156(128-228)$ & $154(124-236)$ & 0.990 \\
\hline $\mathrm{HDL}-\mathrm{C}, \mathrm{mmol} / \mathrm{L}$ & $1.29-1.55$ & $0.9(0.8-1.2)$ & $1.1(0.9-1.3)$ & $0.9(0.7-1.0)$ & 0.000 \\
\hline $\mathrm{LDL}-\mathrm{C}, \mathrm{mmol} / \mathrm{L}$ & $<3.12$ & $2.6(2.2-3.0)$ & $2.6(2.1-3.0)$ & $2.7(2.2-3.0)$ & 0.615 \\
\hline Plasma glucose, mmol/L & $3.89-5.83$ & $6.7(5.7-8.2)$ & $5.8(5.2-7.5)$ & $7.4(6.1-9.1)$ & 0.000 \\
\hline Serum sodium, mmol/L & $135-145$ & $137.2(135-140)$ & $138(136-140)$ & $137(134-140)$ & 0.119 \\
\hline Serum potassium, mmol/L & $3.5-5.5$ & $3.4(3.2-3.6)$ & $3.5(3.3-3.6)$ & $3.3(3.1-3.6)$ & 0.005 \\
\hline Creatinine, $\mu \mathrm{mol} / \mathrm{L}$ & $44-120$ & $65(52-76)$ & $61(51-72)$ & $6(52-79)$ & 0.175 \\
\hline BUN, mmol/L & $2.5-6.7$ & $3.6(2.7-5.2)$ & $3.5(2.7-4.8)$ & $4.02(2.7-5.2)$ & 0.225 \\
\hline TBIL, mmol/L & $3.4-20.5$ & $14.4(10.3-20.0)$ & $13.5(8.0-16.4)$ & $16.2(13.4-21.8)$ & 0.000 \\
\hline Albumin, g/L & $34-54$ & $36.0(31.7-39.4)$ & $39.0(36.9-40.0)$ & $32.0(30.2-34.0)$ & 0.000 \\
\hline AST, U/L & $8-40$ & $51.0(34.1-72.6)$ & $42.6(30.3-56.8)$ & $61.0(43.5-87.0)$ & 0.000 \\
\hline$A L T, U / L$ & $5-35$ & $40.0(22.0-62.4)$ & $35.8(18.3-46.7)$ & $50.0(28.8-76.8)$ & 0.002 \\
\hline $\mathrm{LDH}, \mathrm{U} / \mathrm{L}$ & $109-245$ & $256(178-354)$ & $214(153-257)$ & $321(256-471)$ & 0.000 \\
\hline CK-MB, U/L & $0-25$ & $12.3(9.8-19.1)$ & $11.5(9.8-16.7)$ & $12.8(9.9-20.6)$ & 0.134 \\
\hline D-dimer, ug/mL & $0-1$ & $0.5(0.4-1.5)$ & $0.4(0.3-0.7)$ & $1.2(0.5-2.9)$ & 0.000 \\
\hline APTT, s & $20-40$ & $27.4(24-31.5)$ & $26.2(23.8-31.5)$ & $27.6(24.2-30.7)$ & 0.477 \\
\hline PT, s & $9-14$ & $11.2(10.8-12.4)$ & $11.1(10.5-12.3)$ & $11.4(10.8-12.9)$ & 0.347 \\
\hline $\mathrm{ESR}, \mathrm{mm} / \mathrm{h}$ & $0-20$ & $37.4(18.1-62.4)$ & $25.4(16.7-48.6)$ & $44.7(21.4-81.0)$ & 0.001 \\
\hline SAA, mg/L & $0.1-10$ & $185.0(26.1-638.9)$ & $40.6(13.6-141.0)$ & 477.7 (209-996) & 0.000 \\
\hline CRP, mg/L & $0-5$ & $15.3(5.0-69.1)$ & $8.6(4.7-28.6)$ & $54.8(11.5-100.5)$ & 0.000 \\
\hline $\mathrm{PCT}, \mathrm{ng} / \mathrm{mL}$ & $<0.04$ & & & & 0.000 \\
\hline$<0.04, \mathrm{n}(\%)$ & & $85(59.4)$ & $55(76.4)$ & $30(42.3)$ & \\
\hline $0.04-0.25, \mathrm{n}(\%)$ & & $39(27.3)$ & $12(16.7)$ & $27(38.0)$ & \\
\hline $0.25-0.5, \mathrm{n}(\%)$ & & $14(9.8)$ & $4(5.6)$ & $10(14.1)$ & \\
\hline$\geq 0.5, \mathrm{n}(\%)$ & & $5(3.5)$ & $1(1.4)$ & $4(5.6)$ & \\
\hline
\end{tabular}

Abbreviations: $H D L-C$ high-density lipoprotein cholesterol, LDL-C low-density lipoprotein cholesterol, BUN blood urea nitrogen, TBIL total bilirubin, $A S T$ aspartate aminotransferase, $A L T$ alanine aminotransferase, $L D H$ lactate dehydrogenase, $C K-M B$ creatine kinase-muscle and brain type, $A P T T$ activated partial thromboplastin time, $P T$ prothrombin time, ESR erythrocyte sedimentation rate, SAA serum amyloid A, CRP C-reactive protein, $P C T$ procalcitonin, IQR interquartile range, COVID-19 Coronavirus disease 2019

${ }^{a} P$ values indicate differences between mild/moderate and severe/critical. $P<0.05$ was considered statistically significant

negative correlation between disease severity and lymphocyte count, albumin, serum potassium, and HDL-C (Table 3). Age $(r=0.458)$, comorbidities $(r=$ $0.445)$, LDH $(r=0.548)$, D-dimer $(r=0.477)$, SAA $(r=$ $0.58)$, CRP $(r=0.477)$ were moderately correlated and albumin $(r=-0.603)$ was highly correlated.

To better detect the severe illness, the ROC curve of age was administrated and listed in Fig. 2a (AUC= 0.746, 95\% CI: $0.686-0.831, P<0.001)$. The best cut-off point of age was 52 years with a sensitivity of $76.1 \%$ and specificity of $63.9 \%$. The ROC curve of LDH (AUC =
0.816, 95\% CI: $0.743-0.876, P<0.001$, Fig. $2 b)$ suggested the best cut-off point was $245 \mathrm{U} / \mathrm{L}$ with a specificity of $69.4 \%$ and a sensitivity of $85.9 \%$. The ROC curve of Ddimer $(\mathrm{AUC}=0.775$, 95\% CI: 0.698-0.841, $P<0.001$, Fig. 2c) suggested the best cut-off point was $0.96 \mu \mathrm{g} / \mathrm{mL}$ with $77.0 \%$ specificity and $78.1 \%$ sensitivity. The ROC curve of SAA (AUC $=0.835,95 \%$ CI: $0.764-0.892, P<$ 0.001 , Fig. 2d) indicated the best cut-off point was $100.02 \mathrm{mg} / \mathrm{L}$ with $72.2 \%$ specificity and $85.9 \%$ sensitivity. The ROC curve of albumin (AUC $=0.848,95 \% \mathrm{CI}$ : 0.779-0.903, $P<0.001$, Fig. 2e) indicated the best cut-off 
Table 3 Correlation coefficient and $P$ value between items and disease severity

\begin{tabular}{lll}
\hline & $r$ & $P$ \\
\hline Age & 0.458 & 0.000 \\
Comorbidities & 0.445 & 0.000 \\
White blood cell count & 0.229 & 0.006 \\
Neutrophil count & 0.238 & 0.004 \\
Lymphocyte count & -0.295 & 0.000 \\
HDL-C & -0.362 & 0.000 \\
Plasma glucose & 0.383 & 0.000 \\
Serum potassium & -0.237 & 0.004 \\
TBIL & 0.340 & 0.000 \\
Albumin & -0.603 & 0.000 \\
AST & 0.342 & 0.000 \\
ALT & 0.264 & 0.001 \\
LDH & 0.548 & 0.000 \\
D-dimer & 0.477 & 0.000 \\
ESR & 0.284 & 0.001 \\
SAA & 0.58 & 0.000 \\
CRP & 0.477 & 0.000 \\
PCT & 0.345 & 0.000 \\
Abbrevations:HDLC, & &
\end{tabular}

Abbreviations: HDL-C, high-density lipoprotein cholesterol, TBIL total bilirubin, AST aspartate aminotransferase, ALT alanine aminotransferase, $L D H$ lactate dehydrogenase, ESR erythrocyte sedimentation rate, SAA serum amyloid A, CRP c-reactive protein, $P C T$ procalcitonin

point was $36 \mathrm{~g} / \mathrm{L}$ with a specificity of $83.3 \%$ and a sensitivity of $85.9 \%$. The ROC curve of CRP (AUC $=0.776$, 95\% CI: $0.698-0.841, P<0.001$, Fig. 2f) suggested the best cut-off point was $64.79 \mathrm{mg} / \mathrm{L}$ with a specificity of $81.9 \%$ and a sensitivity of $64.8 \%$.

The area under the ROC curve for albumin was the biggest $(\mathrm{AUC}=0.848$ ), and the area under the ROC curve for SAA ranked second (AUC $=0.835$ ). The calculated difference between the AUC for albumin and the AUC for SAA was 0.013, but it was not statistically significant $(P=0.787)$. Binary logistic regression was applied to calculate the predictive probability of combined indicators for the speculation of disease severity. The combined indicators found that the AUC reached 0.921 (95\% CI: 0.864-0.959, $P<0.001$, Fig. 3a), with a sensitivity of $87.3 \%$ and a specificity of $80.6 \%$. The area difference between the combined indicators and albumin was 0.0726 (95\% CI: 0.0125-0.133, $P=0.0179$, Fig. 3b), indicating that the accuracy of the combined identification of the six indicators was the best.

\section{Discussion}

The SARS-CoV-2 outbreaking at the end of 2019 is highly contagious and more than 80,000 patients have been reported in Chinese mainland [9]. The number of confirmed cases worldwide has risen by 7499 to 132,758 , among which nearly 28,900 were reported in the European region [10]. Most patients are mild to moderate severity, and with a better prognosis [11]. However, for patients developing into severe or critical levels, the mortality rate was markedly higher. It is important to identify critically ill patients even earlier, aiming to reduce mortality and improve the recovery rate.

In this study, the relationship between disease severity and clinical and biochemical indicators was comprehensively analyzed. Most critical ill patients were older and had a greater number of comorbid conditions than patients with mild to moderate illness. This was consistent with a study [7] in which prospectively included 138 patients with COVID-19 and the researcher suggested that age and comorbidity may be risk factors for poor outcome. Moreover, our study showed that the ROC curve of age was administrated, and the best cut-off point of age was 52 years.

In accordance with Liu J's [12] and Wan S's [13] study, this study also found that the levels of lymphocyte count, neutrophil count and CRP were associated with the severity of COVID-19. In addition, ESR, PCT, Ddimer and SAA were also related to the disease severity. PCT levels in serum increase when severe bacterial, fungal and systemic inflammatory response syndrome occur, and it is generally not elevated with virus infections [14]. In our study, the PCT concentration in severe/critical patients was significantly higher than that in the mild/moderate group when $\mathrm{PCT} \geq 0.04 \mathrm{ng} / \mathrm{mL}$. It suggested the possibility of multiple infections in critically ill patients.

Besides, we also found that the levels of HDL-C and serum potassium were negatively correlated with the severity of COVID-19. According to Dong C's [15] study, hypokalemia was prevailing in patients with COVID-19, and the correction of hypokalemia was challenging because of continuous renal $\mathrm{K}+$ loss resulting from the degradation of ACE2. HDL-C was known to play protective role in a variety of disease states, including viral pneumonia [16]. Serum HDL-C levels might decrease and serum total cholesterol/HDL-C ratios might increase proportionally in community-acquired pneumonia [17]. According to Wei C's [18] study, the spike protein of SARS-CoV-2 bound to HDL and antagonists of HDL receptor-Scavenger receptor class B type I inhibited SARS-CoV-2 infection. The lipids transfer function of Scavenger receptor class B type I was indispensable for this inhibition, providing explanations for the reduced serum HDL level in patients with COVID-19. In a retrospective study [19] reporting on 97 adults with laboratory-confirmed COVID-19, Decrease in HDL-C was found to be valuable in predicting the transition of COVID-19 from mild to severe illness. Similar results were obtained in our own research. Therefore, serum 

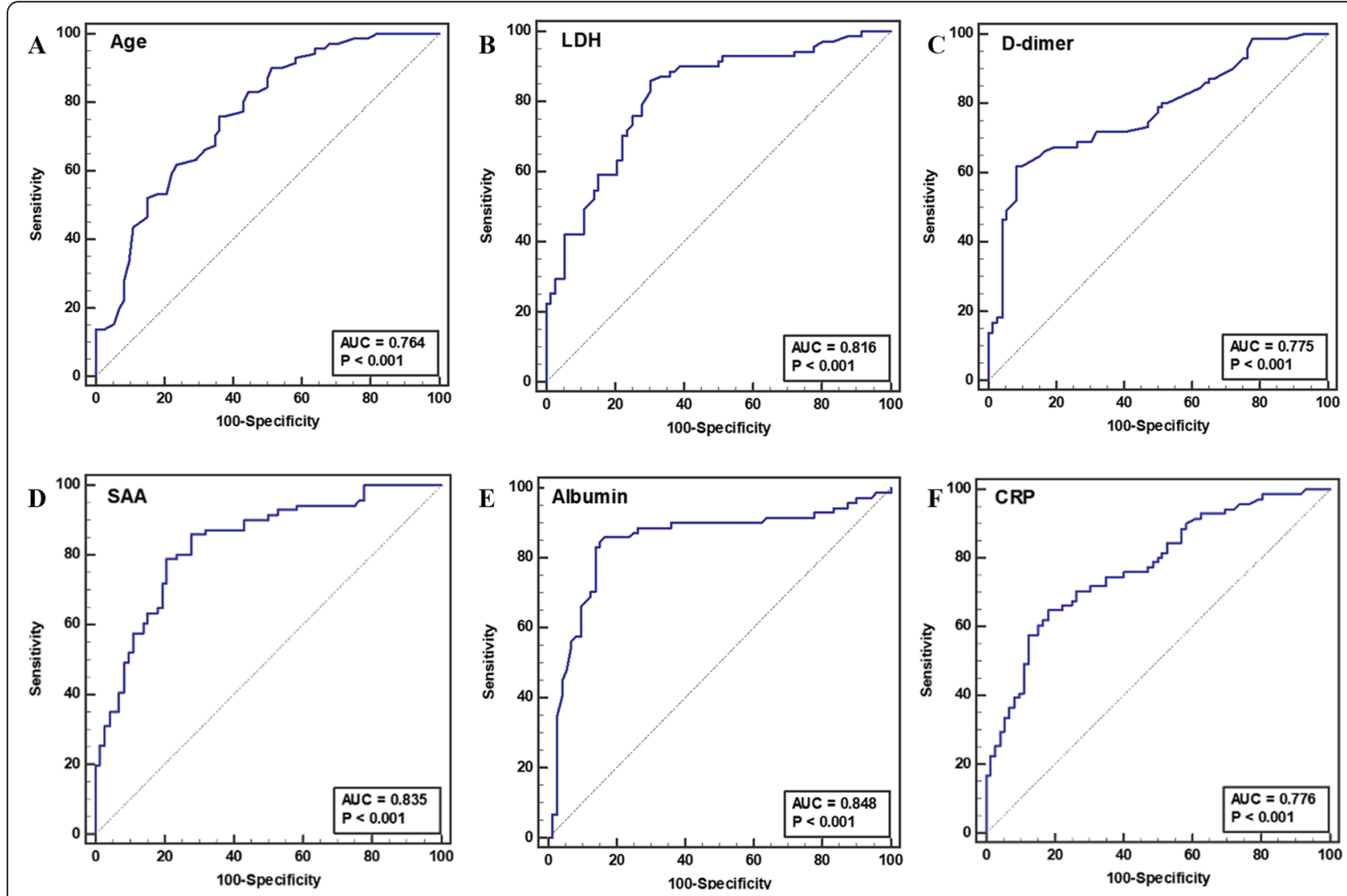

Fig. 2 ROC curve of indicators between mild/moderate and severe/critical. a age; b LDH; c D-dimer; $\mathbf{d}$ SAA; e Albumin; f CRP
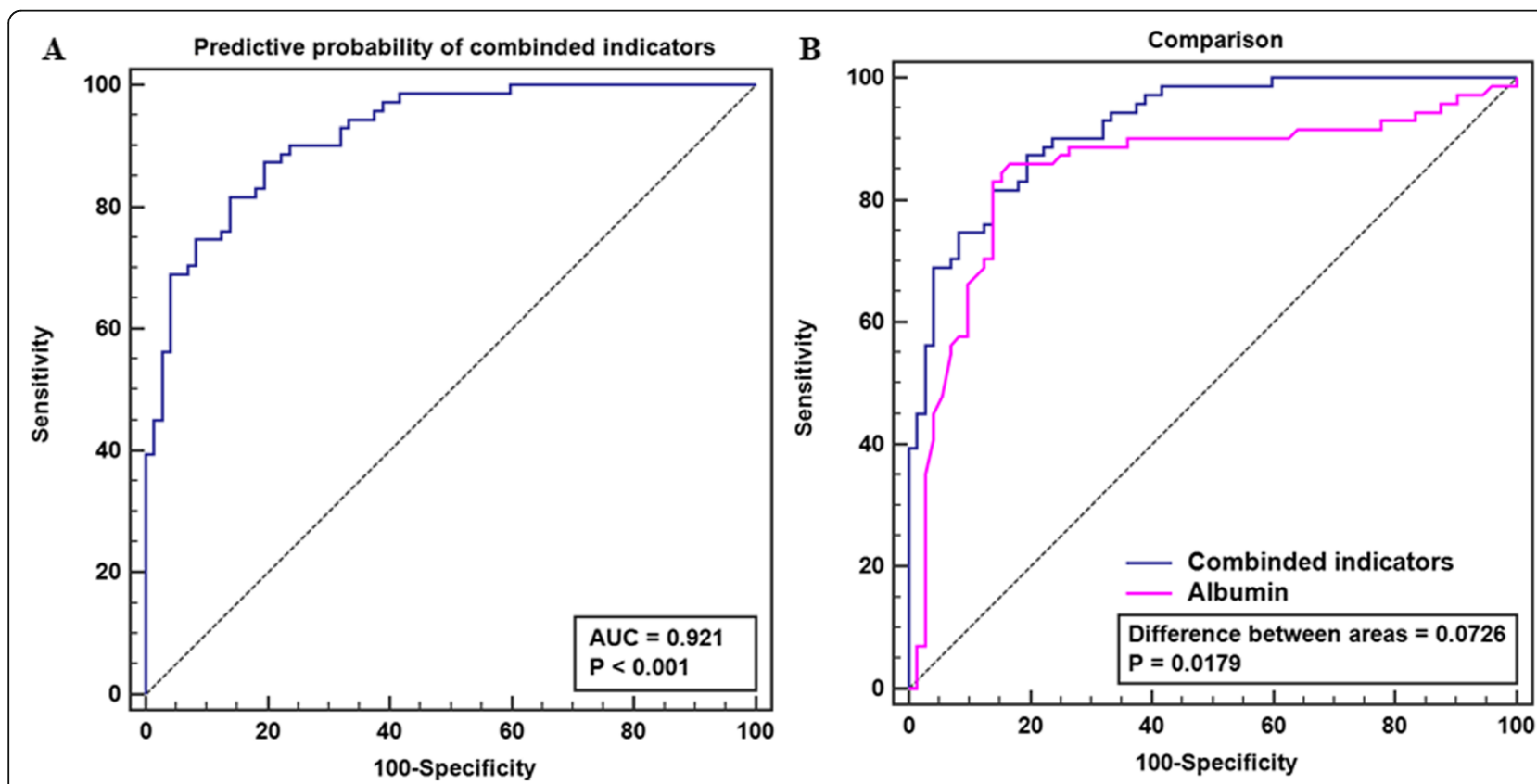

Fig. 3 ROC curve of combined indicators for the speculation of disease severity 
potassium and HDL-C levels may be a good prognostic index.

In this study, there were also some other abnormal indicators that had significant differences between the mild/moderate and the severe/critical group, such as plasma glucose, TBIL, AST, ALT, and LDH. These abnormalities suggested that SARS-CoV-2 infection may be associated with myocardia injury, hepatic injury and other related organ damage. Based on the ROC analysis between mild/moderate and severe/critical patients, some cut-off values of the test items were obtained. With age $>52$ years, CRP $>64.79 \mathrm{mg} / \mathrm{L}, \mathrm{LDH}>245 \mathrm{U} / \mathrm{L}$, D-dimer $>0.96 \mu \mathrm{g} / \mathrm{mL}, \mathrm{SAA}>100.02 \mathrm{mg} / \mathrm{L}$, albumin $<$ $36 \mathrm{~g} / \mathrm{L}$, progress to critical illness should be closely observed and prevented.

According to Lu J's study [5], a simple mortality risk index, composed of age and CRP, can predict COVID19 related short-term mortality. In a retrospective cohort study [20] reporting on 191 adult inpatients with laboratory-confirmed COVID-19, multivariable regression showed increasing odds of in-hospital death associated with older age (odds ratio 1.10, 95\% CI 1.03-1.17, per year increase; $p=0.0043$ ) and $\mathrm{D}$-dimer greater than $1 \mu \mathrm{g} / \mathrm{mL}(18.42,2.64-128.55 ; p=0.0033)$ on admission. According to $\mathrm{Wu}$ C's study [21], for the patients with COVID-19, risk factors associated with the development of ARDS and progression from ARDS to death included older age (hazard ratio [HR], 3.26; 95\% CI 2.08-5.11; and HR, 6.17; 95\% CI, 3.26-11.67, respectively), higher LDH (HR, 1.61; 95\% CI, 1.44-1.79; and HR, 1.30; 95\% CI, 1.11-1.52, respectively) and D-dimer (HR, 1.03; 95\% CI, 1.01-1.04; and HR, 1.02; 95\% CI, 1.01-1.04, respectively). So far, no study has shown plasma glucose, TBIL, AST and ALT were independent risk factors for COVID-19 progression. It is possible that these may be confounding factors, which still needs to be further confirmed.

According to the above, patients' conditions on admission including old age, comorbidities, lymphocytopenia, hypoalbuminemia, and other abnomal indicators may predict the severity of the disease. These factors need further investigation and should be considered for risk stratification. We have found that COVID-19 progressed rapidly for some critically ill patients. Therefore, for those at high risk, close monitoring and timely treatment might be very important and could help to improve the outcome.

This study has several limitations. First, it is a pity that some inflammatory factors and immunological indexes cannot be detected and compared due to the limitation of experimental conditions. Second, this is a crosssectional study and participants were from 1 center rather than multiple centers. It provides no information regarding cause or effect relationship. Although we found significant associations, further studies are needed to investigate clinical significance of these indicators on patients with COVID-19.

\section{Conclusions}

With following parameters such as age $>52$ years, C-reactive protein $>64.79 \mathrm{mg} / \mathrm{L}$, lactate dehydrogenase $>245 \mathrm{U} / \mathrm{L}$, Ddimer $>0.96 \mu \mathrm{g} / \mathrm{mL}$, serum amyloid A $>100.02 \mathrm{mg} / \mathrm{L}$, or albumin $<36 \mathrm{~g} / \mathrm{L}$, the progress of COVID-19 to critical stage should be closely observed and possibly prevented. Lymphocyte count, serum potassium, high-density lipoprotein cholesterol and procalcitonin may also be a prognostic indicator.

\section{Abbreviations}

COVID-19: Coronavirus disease 2019; SARS-CoV-2: Severe acute respiratory syndrome coronavirus 2; WHO: World Health Organization; ARDS: Acute respiratory distress syndrome; ICU: Intensive care unit; ESR: Erythrocyte sedimentation rate; CRP: C-reactive protein; PCT: Procalcitonin;

IQR: Interquartile range; ROC: Receiver-operating characteristic; HDL-C: Highdensity lipoprotein cholesterol; LDL-C: Low-density lipoprotein cholesterol;

TBIL: Total bilirubin; AST: Aspartate aminotransferase; ALT: Alanine aminotransferase; LDH: Lactate dehydrogenase; SAA: Serum amyloid A BUN: Blood urea nitrogen; CK-MB: Creatine kinase-muscle and brain type; APTT: Activated partial thromboplastin time; PT: Prothrombin time; AUC: Area under the ROC curve; HR: Hazard ratio

\section{Acknowledgements}

We thank Lianglong Peng for his reviewing and editing the diagrams and images.

\section{Authors' contributions}

WD was responsible for the conception and design of the study. WD, HQ and LG were responsible for acquisition and analysis of data; furthermore, WD, WJ and QJ were in charge of statistical analysis. WD and $\mathrm{YJ}$ took part in drafting the manuscript; GC and RL participated in the interpretation of the data and approved the final version of the manuscript. All authors read and approved the final manuscript.

\section{Funding}

None.

\section{Availability of data and materials}

All data generated or analyzed during this study are included in this published article. The datasets used and/or analysed during the current study are available from the corresponding author on reasonable request.

\section{Ethics approval and consent to participate}

This study was approved by the medical ethics committee of Hubei NO.3 People's Hospital of Jianghan University, and all participants provided informed verbal consent. The consent obtained was verbal because of the the infectivity and the exploration urgency for COVID-19. We obtained the verbal consent of the patient or his immediate family members by telephone and the ethics committee approved this procedure.

Consent for publication

Not applicable.

\section{Competing interests}

The authors declare that they have no competing interests.

\section{Author details}

'Department of Neurology, Hubei NO.3 People's Hospital of Jianghan University, 26 Zhongshan Road, Qiaokou District, Wuhan, China. ${ }^{2}$ Department of Radiology, Tongji Hospital, Huazhong University of Science and Technology, Wuhan, China. ${ }^{3}$ Department of Infectious Diseases, Zhongnan Hospital of Wuhan University, Wuhan, China. 
Received: 25 March 2020 Accepted: 7 July 2020

Published online: 16 July 2020

\section{References}

1. Huang C, Wang Y, Li X, Ren L, Zhao J, Hu Y, Zhang L, Fan G, Xu J, Gu X, et al. Clinical features of patients infected with 2019 novel coronavirus in Wuhan, China. Lancet. 2020;395(10223):497-506.

2. National Health Commission of the People's Republic of China. Notice on the novel coronavirus infection diagnosis and treatment plan (trial version sixth). In: National Health Commission of the People's Republic of China, editor. Beijing, 2020. Available from: http://www.nhc.gov.cn/wjw/gfxwjj/ list_5.shtml. Accessed 10 Mar 2020.

3. National Health Commission Stroke Prevention and Control Engineering Expert Committee. Expert consensus on prevention and control of novel coronavirus infection in neurology (version first). In: National Health Commission Stroke Prevention and Control Engineering Expert Committee, editor. Beijing, 2020. Available from: http://www.sinosc.org/NewsInfo/News/ NewsDetailWeb?Tid=2621. Accessed 10 Mar 2020.

4. Chen N, Zhou M, Dong X, Qu J, Gong F, Han Y, Qiu Y, Wang J, Liu Y, Wei Y, et al. Epidemiological and clinical characteristics of 99 cases of 2019 novel coronavirus pneumonia in Wuhan, China: a descriptive study. Lancet. 2020; 395(10223):507-13.

5. Lu J, Hu S, Fan R, Liu Z, Yin X, Wang Q, Lv Q, Cai Z, Li H, Hu Y, et al: ACP risk grade: a simple mortality index for patients with confirmed or suspected severe acute respiratory syndrome coronavirus 2 disease (COVID-19) during the early stage of outbreak in Wuhan, China. https://www.medrxiv.org/ content/10.1101/2020.02.20.20025510v1 (2020). Accessed 23 Mar 2020.

6. Liu J, Liu Y, Xiang P, Pu L, Xiong H, Li C, Zhang M, Tan J, Xu Y, Song R, et al: Neutrophil-to-Lymphocyte Ratio Predicts Severe IIIness Patients with 2019 Novel Coronavirus in the Early Stage. https://www.medrxiv.org/content/1 0.1101/2020.02.10.20021584v1 (2020). Accessed 23 Mar 2020

7. Wang D, Hu B, Hu C, Zhu F, Liu X, Zhang J, Wang B, Xiang H, Cheng Z, Xiong Y, et al. Clinical characteristics of 138 hospitalized patients with 2019 novel coronavirus-infected pneumonia in Wuhan, China. JAMA. 2020. https://doi.org/10.1001/jama.2020.1585.

8. National Health Commission of the People's Republic of China. Notice on the novel coronavirus infection diagnosis and treatment plan (trial version seventh). In: National Health Commission of the People's Republic of China, editor. Beijing, 2020. Available from: http://www.nhc.gov.cn/wjw/gfxwjj/ list_5.shtml. Accessed 18 Mar 2020.

9. China Daily Network. Big data on COVID-19 around the world. Available from: https://www.chinadaily.com.cn/china/special_coverage/2020latestdata. Accessed 11 Mar 2020.

10. China Daily Network. COVID-19 confirmed cases top 50,000 outside China Available from: https://www.chinadaily.com.cn/a/202003/14/WS5e6c2687a31 012821727f108.html. Accessed 14 Mar 2020

11. Team NCPERE. The epidemiological characteristics of an outbreak of 2019 novel coronavirus diseases (COVID-19) in China. Zhonghua Liu Xing Bing Xue Za Zhi. 2020;41(2):145-51.

12. Liu J, Li S, Liu J, Liang B, Wang X, Wang H, Li W, Tong Q, Yi J, Zhao L, et al. Longitudinal characteristics of lymphocyte responses and cytokine profiles in the peripheral blood of SARS-CoV-2 infected patients. EBioMedicine. 2020. https://doi.org/10.1016/j.ebiom.2020.102763.

13. Wan S, Yi Q, Fan S, Lv J, Zhang X, Guo L, Lang C, Xiao Q, Xiao K, Yi Z, et al: Characteristics of lymphocyte subsets and cytokines in peripheral blood of 123 hospitalized patients with 2019 novel coronavirus pneumonia (NCP). https://www.medrxiv.org/content/10.1101/2020.02.10.20021832v1 (2020). Accessed 24 Mar 2020.

14. Albrich WC, Harbarth S. Pros and cons of using biomarkers versus clinical decisions in start and stop decisions for antibiotics in the critical care setting. Intensive Care Med. 2015;41(10):1739-51.

15. Chen D, Li X, Song Q, Hu C, Su F, Dai J: Hypokalemia and Clinical Implications in Patients with Coronavirus Disease 2019 (COVID-19). https:// www.medrxiv.org/content/10.1101/2020.02.27.20028530v1 (2020). Accessed 25 Mar 2020.

16. Gordon EM, Figueroa DM, Barochia AV, Yao X, Levine SJ. High-density lipoproteins and Apolipoprotein A-I: potential new players in the prevention and treatment of lung disease. Front Pharmacol. 2016;7:323.

17. Deniz O, Tozkoparan E, Yaman H, Cakir E, Gumus S, Ozcan O, Bozlar U, Bilgi C, Bilgic H, Ekiz K. Serum HDL-C levels, log (TG/HDL-C) values and serum total cholesterol/HDL-C ratios significantly correlate with radiological extent of disease in patients with community-acquired pneumonia. Clin Biochem. 2006:39(3):287-92

18. Wei C, Wan L, Zhang Y, Fan C, Yan Q, Yang X, Gong J, Yang H, Li H, Zhang J, et al: Cholesterol Metabolism--Impact for SARS-CoV-2 Infection Prognosis, Entry, and Antiviral Therapies. https://www.medrxiv.org/content/10.1101/202 0.04.16.20068528v2 (2020). Accessed 1 May 2020.

19. Nie S, Zhao X, Zhao K, Zhang Z, Zhang Z, Zhang Z: Metabolic disturbances and inflammatory dysfunction predict severity of coronavirus disease 2019 (COVID-19): a retrospective study. https://www.medrxiv.org/content/10.11 01/2020.03.24.20042283v1 (2020). Accessed 1 May 2020.

20. Zhou F, Yu T, Du R, Fan G, Liu Y, Liu Z, Xiang J, Wang Y, Song B, Gu X, et al. Clinical course and risk factors for mortality of adult inpatients with COVID19 in Wuhan, China: a retrospective cohort study. Lancet. 2020;395(10229): 1054-62.

21. Wu C, Chen X, Cai Y, Xia J, Zhou X, Xu S, Huang H, Zhang L, Zhou X, Du C, et al. Risk factors associated with acute respiratory distress syndrome and death in patients with coronavirus disease 2019 pneumonia in Wuhan, China. JAMA Intern Med. 2020. https://doi.org/10.1001/jamainternmed.2020.0994.

\section{Publisher's Note}

Springer Nature remains neutral with regard to jurisdictional claims in published maps and institutional affiliations.

\section{Ready to submit your research? Choose BMC and benefit from:}

- fast, convenient online submission

- thorough peer review by experienced researchers in your field

- rapid publication on acceptance

- support for research data, including large and complex data types

- gold Open Access which fosters wider collaboration and increased citations

- maximum visibility for your research: over $100 \mathrm{M}$ website views per year

At $\mathrm{BMC}$, research is always in progress.

Learn more biomedcentral.com/submissions 